NBER WORKING PAPER SERIES

\title{
THE TERM STRUCTURE OF RETURNS: \\ FACTS AND THEORY
}

Jules H. van Binsbergen

Ralph S.J. Koijen

Working Paper 21234

http://www.nber.org/papers/w21234

\author{
NATIONAL BUREAU OF ECONOMIC RESEARCH \\ 1050 Massachusetts Avenue \\ Cambridge, MA 02138 \\ June 2015
}

For discussions on this topic over the years, we thank Marianne Andries, Jonathan Berk, Michael Jarda Borovicka, Brandt, John Campbell, Darrell Duffie, Xavier Gabaix, Stefano Giglio, Francisco Gomes, Lars Hansen, John Heaton, Wouter Hueskes, Minsoo Kim, Howard Kung, Martin Lettau, Sydney Ludvigson, Hanno Lustig, Matteo Maggiori, Toby Moskowitz, Lasse Pedersen, Monika Piazzesi, Martin Schmalz, Ken Singleton, Stijn Van Nieuwerburgh, Evert Vrugt, Jessica Wachter, and Moto Yogo. We thank Jonathan Wright, Luis Viceira, Carolin Pflueger, and Christian Glissman-Mueller for generously sharing data for this project. Koijen acknowledges financial support from the European Research Council (grant 338082). The views expressed herein are those of the authors and do not necessarily reflect the views of the National Bureau of Economic Research.

NBER working papers are circulated for discussion and comment purposes. They have not been peerreviewed or been subject to the review by the NBER Board of Directors that accompanies official NBER publications.

(C) 2015 by Jules H. van Binsbergen and Ralph S.J. Koijen. All rights reserved. Short sections of text, not to exceed two paragraphs, may be quoted without explicit permission provided that full credit, including (O) notice, is given to the source. 
The Term Structure of Returns: Facts and Theory

Jules H. van Binsbergen and Ralph S.J. Koijen

NBER Working Paper No. 21234

June 2015

JEL No. G12

\begin{abstract}
We summarize and extend the new literature on the term structure of equity. Short-term equity claims, or dividend strips, have on average significantly higher returns than the aggregate stock market. The returns on short-term dividend claims are risky as measured by volatility, but safe as measured by market beta. These facts are hard to reconcile with traditional macro-finance models and we provide an overview of new models that can reproduce some of these facts. We relate our evidence on dividend strips to facts about other asset classes such as nominal and corporate bonds, volatility, and housing. We conclude by discussing the broader economic implications by linking the term structure of returns to real economic decisions such as hiring and investment.
\end{abstract}

Jules H. van Binsbergen

The Wharton School

University of Pennsylvania

3620 Locust Walk

Philadelphia, PA 19104

and NBER

julesv@wharton.upenn.edu

Ralph S.J. Koijen

London Business School

Regent's Park

London NW1 4SA

United Kingdom

rkoijen@london.edu 


\section{INTRODUCTION}

The discounted value of future cash flows plays a central role in financial and real investment decisions. As initially pointed out by Brennan (1998), observing assets that pay off a single dividend of a stock index at a future point in time could help to promote rational pricing. Building on these insights, a literature has developed in recent years to measure the term structure of equity. In this paper, we review and extend this literature and discuss both the empirical facts as well as the theoretical explanations that have been proposed. We also connect the properties of the term structure of equity to term structures in other asset classes such as nominal and corporate bonds, volatility, and housing.

Initial measurements of the term structure of equity are based on portfolios of stocks with different cash flow growth rates and risk properties, see Cornell (1999), Dechow, Sloan, and Soliman (2004), Bansal, Dittmar, and Lundblad (2005), Lettau and Wachter (2007), Hansen, Heaton, and Li (2008), Da (2009), and Chen (2014). An important motivation for this literature is the value premium, which refers to the empirical fact that stocks with low market-to-book ratios have higher average returns than stocks with high market-to-book ratios, despite having similar Capital Asset Pricing Model (CAPM) betas. If the cash flows of value stocks have different average growth rates and risk exposures than the cash flows of growth stocks, then comparing the returns on value and growth stocks can indeed be informative about the term structure of equity.

Instead of relying on the cross-section of stock returns and additional assumptions about the dynamics of cash flows, Binsbergen, Brandt, and Koijen (2012, BBK) provide the first direct measurement of dividend strip prices. The main insight is that put-call parity for European stocks implies that

$$
C_{t, n}(K)+K e^{-y_{t, n} n}=P_{t, n}(K)+S_{t}-\mathcal{P}_{t, n},
$$

where $C_{t, n}(K)$ and $P_{t, n}(K)$ are the time- $t$ prices of call and put options, respectively, that mature in $n$ periods with a strike price $K$. The variable $y_{t, n}$ denotes the $n$-period bond yield at time $t$ and $S_{t}$ denotes the index value at time $t$. Lastly, and most importantly, $\mathcal{P}_{t, n}$ measures the net present value of dividends paid out over the life of the option, which are the prices of dividend strips. ${ }^{1}$ To measure dividend prices precisely, BBK use high-frequency Trade-and-Quote (TAQ) data to ensure that put, call, and index prices are all measured at exactly the same time.

\footnotetext{
${ }^{1}$ A similar calculation can be performed using futures prices using the cost of carry formula, see also Golez (2014).
} 
Binsbergen, Hueskes, Koijen, and Vrugt (2014, BHKV) extend this evidence using dividend futures, which were introduced around the turn of the millennium for the S\&P500, Eurostoxx 50, and the Nikkei 225 index. A long position in a dividend futures contract implies that in exchange for a known payment due in $n$ years from now, one receives the dividends paid on the underlying index over the year leading up to the settlement. For the Eurostoxx 50 index, dividend futures are exchange traded since 2008. They allow for direct measurement of dividend strip prices without the need for high-frequency data for options and the stock index. A second important advantage is that dividend futures have longer maturities of up to 10 years, although the liquidity declines for the longest maturities. The maximum maturity for options is about three years.

BHKV use dividend futures prices to define equity yields as:

$$
e y_{t, n} \equiv \frac{1}{n} \ln \left(D_{t, n} / F_{t}\right)=\theta_{t, n}-g_{t, n}
$$

where $F_{t, n}$ is the $n$-period dividend futures price and $D_{t}$ the level of dividends at time $t$. The equity yield, $e y_{t, n}$ contains a risk premium component $\theta_{t, n}$, which equals the expected log return on a dividend futures contract with maturity $n$, and a component that reflects expected log dividend growth, $g_{t, n}$. BHKV show that both risk premia and expected growth rates fluctuate over time, and that risk premia are strongly counter-cyclical. The expected growth component $g_{t, n}$ is useful for predicting future dividends, GDP growth, and consumption growth, over and above the predictive power of nominal and real bond yields.

In this paper, we first extend the sample of BHKV in the time series dimension as well as cross-sectionally by adding evidence from the UK (the FTSE 100 index). Using this extended sample, we document three key facts in the data:

1. Both risk premia and Sharpe ratios are higher for short-maturity claims than for the aggregate stock market. If we form a world portfolio of dividend strips by averaging across the four markets for which data exists, the difference in risk premia between this portfolio and a portfolio of index returns is statistically significantly positive at conventional significance levels. The results are strongest for the most liquid market, which is the Eurostoxx 50. The difference is statistically insignificant for the Nikkei 225, the FTSE 100, and the S\&P500 individually, the latter of which is consistent with the findings in BBK.

2. The returns on short-term dividend claims are risky as measured by volatility, but safe as measured by market betas. The volatility of dividend strip returns is as high, if 
not higher, than the volatility of market returns. However, the market betas are well below one and increasing with maturity.

3. The volatility of equity yields is downward sloping with maturity.

Note that the high volatility of dividend strip returns and the low correlation with the market implies that we have relatively little power to reject the null that dividend strip returns are on average higher than market returns. To gain power, we pool data across indices and across short-term maturities, leading to statistically significant outperformance of short-maturity dividend strips over index returns.

In the second part of this paper, we discuss tests of various macro-finance models that have been successful at explaining many facts about asset markets, including the equity risk premium, excess volatility, and both the level and volatility of the risk-free rate. BBK show that leading asset pricing models such as Campbell and Cochrane (1999) and Bansal and Yaron (2004) have counterfactual predictions regarding the first two facts that we list, and see also Lettau and Wachter (2007) who already provide similar calculations for the Campbell and Cochrane (1999) model. The variable rare disaster models of Gabaix (2009) implies that expected returns are independent of maturity, while the volatility of returns is increasing with maturity. ${ }^{2}$

We now propose more powerful tests of these models, which we implement for the external habit model for illustrative purposes. First, if we simulate from the model, then the probability that over a 12-year period a portfolio of short-term dividend strips outperforms the aggregate market is low and equal to $1.3 \%$. An average annual outperformance of 5-8\%, which is what we find in the data, is a 5-8 standard deviation event under the null that the model is correct. We therefore conclude that the habit formation model is most likely not able to match the facts on the term structure of equity.

Another way to reject the model is to use a volatility-based test. The insignificance of the difference between dividend strips and the market for some of the markets individually is the direct consequence of the fact that dividend strips are very risky in the data. In the model, on the other hand, they are much less risky. Hence, the fact that we do not find a significant difference between dividend futures returns and the market for these regions is in fact a rejection of the model along a different dimension and we present a simple volatility test based on equity yields instead of returns. In the external habit formation model, the volatility of equity yields is an order of magnitude lower than in the data and generally upward-sloping with maturity. The economic intuition is simple. Using equation (2), it is straightforward to

\footnotetext{
${ }^{2}$ See also Wachter (2010).
} 
see that equity yields derive their variance either from variation in expected growth rates or variation in risk premia, or both. In the external habit model, log dividend growth is assumed to be unpredictable, implying that $g_{t, n}=g$ for all $n$. Furthermore, the risk premium of shortmaturity dividend claims $\theta_{t, n}$ is close to zero and, most importantly, hardly fluctuates over time. As in the model overall the variance of $\theta_{t, n}$ is generally increasing with maturity, the volatility of equity yields is also increasing with maturity.

We can conclude that even if we ignore the evidence on the average risk premium at the short end of the equity curve, equity yield data can be used to construct a powerful test for macro-finance models in general, and the habit formation model in particular. Of course, it could be that all variation in equity yields is due to expected growth rate variation, and therefore the habit formation model could be made consistent with the data by introducing predictable dividend growth. ${ }^{3}$ However, the results in BHKV suggest that both the risk premium and the expected growth rate fluctuate strongly over time, and that the variance of both the risk premium as well as the expected growth rate declines with maturity.

This leaves us with the question what the economic interpretation of these new facts is. The model proposed by Lettau and Wachter (2007) is consistent with many of the facts we find: the average returns, Sharpe ratios, and volatilities are downward sloping with maturity, while the CAPM beta of short-term dividend assets is well below. However, instead of specifying preferences, Lettau and Wachter (2007) directly specify the stochastic discount factor.

An active new literature proposes new equilibrium asset pricing models to explain these findings. In the third part of this paper, we summarize the different mechanisms. The modifications involve changes in the dynamics of cash flows, preferences, or departures from the representative agent model by introducing interesting forms of heterogeneity. We discuss a variety of papers in each of these categories in Section 5.

The fourth part of the paper extends the empirical evidence across different asset classes. We focus in particular on the first fact that Sharpe ratios are declining with maturity. The idea to use data from multiple asset class as "out-of-sample" evidence has been used recently by Asness, Moskowitz, and Pedersen (2013), Moskowitz, Ooi and Pedersen (2012), and Koijen, Moskowitz, Pedersen, and Vrugt (2014) in the context of other asset pricing anomalies such as value, momentum, and carry. Lettau and Wachter (2011) are the first to propose a model for the term structure of equity and both nominal and real bonds.

\footnotetext{
${ }^{3}$ Cochrane (2008) argues that dividend growth is unpredictable using yield-based variables. For further evidence on dividend growth predictability, see Lettau and Ludvigson (2005), Binsbergen and Koijen (2010), and Rangvid, Schmeling, and Schrimpf (2014).
} 
We provide evidence for nominal and corporate bonds as well as volatility using straddle returns. Data on nominal and corporate bonds are available since 1952 and 1973, respectively, which provides us with a longer sample period than the sample available for dividend strips. We find that Sharpe ratios are declining with maturity in all three asset classes. ${ }^{4}$ The evidence for nominal bonds is consistent with Duffee (2010) and the evidence on volatility aligns with the insights of Ait-Sahalia, Karaman, and Mancini (2013) and Dew-Becker, Giglio, Le, and Rodriguez (2014). Palhares (2013) shows that the Sharpe ratios of credit default swaps (CDS) are declining with maturity. Giglio, Maggiori, and Stroebel (2014) argue that long-term discount rates for housing are low as well.

Over the years many researchers have indicated that the findings in BBK that Sharpe ratios (and risk premia) are downward sloping with maturity are surprising. Given all the available evidence across asset classes, the opposite statement seems to be true: it would actually have been more surprising if Sharpe ratios for equities would increase with maturity, as suggested by traditional macro-finance models.

We conclude this paper by a discussion of interesting avenues for future research using data on the term structure of equities.

\section{Facts and New Evidence About the Term Structure of Dividend Strips}

We first summarize the main findings in BBK. BBK find that short-term dividend strips have performed remarkably well over the sample period 1996-2009 relative to the predictions of several leading asset pricing models. Several leading asset pricing models predict a risk premium for short-term strips close to zero. In addition, BBK document that even relative to the index, dividend strips have performed well, suggesting that the risk premium on dividend strips could even be higher than the equity risk premium. This raises the possibility that the term structure of the equity risk premium is downward sloping for at least part of the maturity space. They further find that CAPM betas of short-term dividend strips are low and around 0.5. As a consequence, relative to commonly used asset pricing models, dividend strips seem to provide attractive Sharpe ratios and alphas. Finally, and perhaps most importantly, BBK find that dividend strip prices are very volatile relative to their subsequent dividend realizations, implying that "excess" volatility also occurs at the short end of the maturity spectrum for stocks, extending the seminal work of Shiller (1981).

\footnotetext{
${ }^{4}$ Average returns are not downward sloping with maturity in all asset classes, as is for instance well known for nominal and corporate bonds.
} 


\subsection{Evidence Based on Options and Dividend Futures}

We start this section by confirming the findings of BBK using dividend futures prices from four different regions: (1) Europe as represented by the Eurostoxx 50 index (SX5E), (2) Japan as represented by the Nikkei 225 index (NKY), (3) the UK as represented by the FTSE 100 index (FTSE), and finally (4) the US as represented by the S\&P500 index (SPX). First, we compute constant maturity dividend future returns. That is, we compute the monthly return on dividend futures of each maturity $n$, where $n$ is measured in months. Due to the annual issuing cycle, consecutive maturities are 12 months apart. The return is given by:

$$
R_{t, n}^{F}=F_{t, n-1} / F_{t-1, n}-1
$$

We then form a weighted average of two consecutive maturities to arrive at a constant maturity return strategy with maturities that are 12 months apart. For example, if in a given month the maturities of the dividend futures contracts are $n=5$ months, 17 months, 29 months, ... , then we simple take a weighted average between returns on these futures contracts with weights equal to 0.4167 and 0.5833 to construct the 12 month, 24 month, 36 month, ... , constant-maturity returns in that month.

To gain power in our tests, we also form an equal-weighted portfolio of short-term constant maturity dividend futures returns,

$$
R_{t, P}^{F} \equiv \frac{R_{t, 12}^{F}+R_{t, 24}^{F}+R_{t, 36}^{F}+R_{t, 48}^{F}+R_{t, 60}^{F}}{5}
$$

Note that dividend futures returns are already excess returns. They are in excess of the corresponding government (default free) bond returns of the same maturity (Binsbergen, Hueskes, Koijen and Vrugt (2013)). Investors in dividend futures contracts thus forego the bond risk premium. This provides an important advantage when studying the compensation for dividend risk across different maturities. Dividend futures prices allow us to separate out the risk and risk premiums for time-varying dividends and our measurement is not contaminated by the risk premium that would have accumulated had dividend payments been constant, that is, the bond risk premium.

As a point of reference, we also include the return on the underlying index returns, which, through the present-value relationship, is a weighted average of dividend strip returns of all maturities. To be consistent with dividend futures contracts which forego the corresponding bond return, we also need to adjust the aggregate index by its corresponding bond return. We show in the appendix that (up to a first-order approximation) the return on the index, 
denoted by $R_{t}^{M}$, can be written as the return on a portfolio of dividend futures returns plus the return on a portfolio of bonds:

$$
R_{t}^{M} \approx \sum_{n=1}^{\infty} w_{t-1, n} R_{t, n}^{F}+\sum_{n=1}^{\infty} w_{t-1, n} R_{t, n}^{B}
$$

where the weights $w_{t, n}$ are given by:

$$
w_{t, n}=\frac{P_{t, n}}{S_{t}}
$$

and $S_{t}$ is the index level, which by no arbitrage is given by:

$$
S_{t}=\sum_{n=1}^{\infty} P_{t, n}
$$

Given the long duration of stocks, we simply approximate the portfolio of bond returns (that is, the second term in (5)) by the 10-year (120-month) constant maturity bond return, but arguably even longer maturities could be considered as well. ${ }^{5}$ The long-term-bond-adjusted market return, $R_{B, t}^{M}$ is then given by:

$$
R_{B, t}^{M} \equiv \frac{1+R_{t}^{M}}{1+R_{t, 120}^{B}}-1,
$$

which corresponds to the basket of dividend future returns.

Using a similar logic, we then use these dividend futures returns to construct dividend spot returns. Let $P_{t, n}$ denote the spot price of a dividend claim that matures in $n$ periods. Then spot and futures prices are linked by the standard no-arbitrage condition:

$$
F_{t, n}=P_{t, n} \exp \left(n y_{t, n}\right)
$$

Let $R_{t, n}^{B}$ denote the one-month return at time $t$ of a bond with maturity $n$, given by:

$$
R_{t, n}^{B}=\frac{\exp \left((n-1) y_{t, n-1}\right)}{\exp \left(n y_{t-1, n}\right)}-1
$$

The no-arbitrage relationship in (7) implies that the dividend spot return $R_{t, n}^{S}$ can be com-

\footnotetext{
${ }^{5}$ For the sample period we consider, picking a longer maturity bond would lower the relative performance of the index.
} 
puted as:

$$
R_{t, n}^{S}=\frac{P_{t, n-1}}{P_{t-1, n}}-1=\left(1+R_{t, n}^{F}\right)\left(1+R_{t, n}^{B}\right)-1
$$

We then also form a portfolio of short-term dividend spot contracts using the first 5 maturities:

$$
R_{t, P}^{S} \equiv \frac{R_{t, 12}^{S}+R_{t, 24}^{S}+R_{t, 36}^{S}+R_{t, 48}^{S}+R_{t, 60}^{S}}{5}
$$

\subsubsection{Results}

Figure 1 plots the cumulative return on constant maturity dividend futures contracts with maturities of 1, 2, 5, and 7 years. For all four regions, dividend strips have performed well suggesting that short-term dividend risks earn a large positive risk premium. As argued above, this finding was first documented by BBK for the U.S. using options data between 1996 and 2009 and seems challenging for many leading asset pricing models. The results in Figure 1 are consistent with this finding. For all regions and for all 4 maturities, dividend futures have outperformed their corresponding index. The findings in BBK therefore do not seem to be a U.S. specific finding and hold across all four regions.

Due to the limited maximum maturity of index options, BBK only compute dividend strips returns for very short-term maturities and compared the average returns of 1.3-1.8 year dividend strips to those of the index, providing only two points along the maturity spectrum, the short-term (1.3-1.8 year dividend strips) and the long-term (the index). Now that we have dividend futures data available for various maturities and regions, we can also compare the average returns of dividend future contracts of various maturities. By comparing the four graphs in Figure 1, it becomes clear that given the available sample, not one consistent pattern arises, and averaging across the regions, the term structure appears pretty flat over the first five years.

One may also be interested in how dividend spot contracts perform. We add to each dividend futures return the corresponding zero-coupon bond return (and thus the bond risk premium of that maturity over the sample period). The results are plotted in Figure 2. As a comparison we also plot the return on the corresponding index, as well as the return on the risk free rate. We include the cumulative performance on the risk free rate because the risk free return is close to the average return predicted for short-maturity dividends by two of the three leading asset pricing models we consider. The results are generally very similar to those of dividend futures contracts. The performance of the index relative to the dividend 

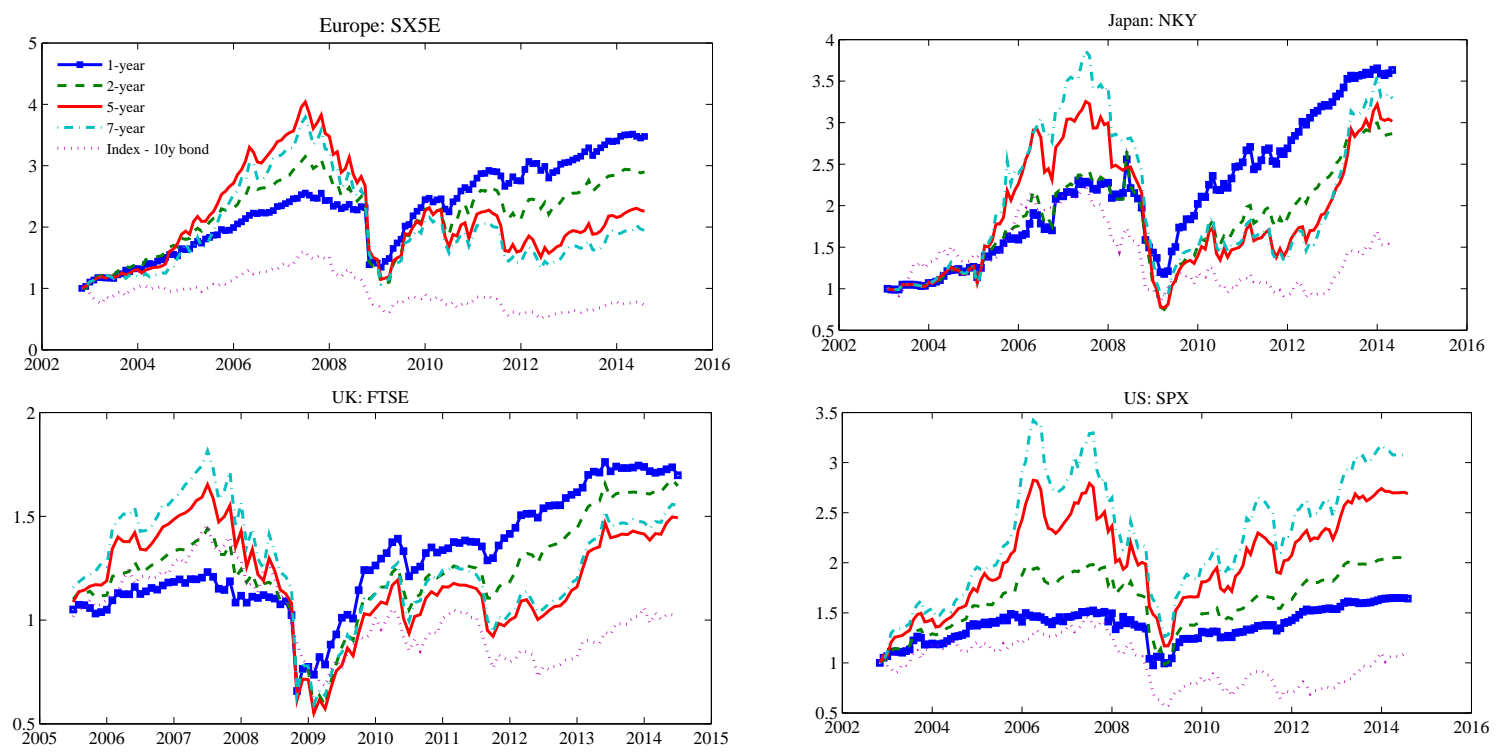

Figure 1: Cumulative Performance Dividend Futures Contracts

The four panels in the figure display the cumulative performance of constant maturity dividend futures contracts with maturities of 1,2,5 and 7 years between 2002 and 2014 for the Europe and the US, between 2003 and 2014 for Japan and between 2006 and 2014 for the UK. Dividend futures returns are excess returns in excess of their corresponding constant maturity zero-coupon bond return. As a comparison we also plot the performance of the index in excess of the long-term (10-year) bond return.

spot contracts improves somewhat, but with the exception of the 1-year contract in the U.S., the index still matches or underperforms dividend spot contracts of all maturities across all regions. For maturities longer than one year, the futures contract is fully exposed to dividend risk. By comparing Figure 1 and 2, it becomes clear that even though the S\&P500 index has performed very well recently in absolute terms, it has not performed that well when compared to long-term bonds, suggesting that the average recent good performance of the index is not a compensation for dividend risk, but rather a reflection of very low long-term risk-free discount rates.

In Table 1, we summarize the properties of dividend futures returns, including their mean, standard deviation, and Sharpe ratio. The Sharpe ratios for each of the indices are lower than for their corresponding short-term dividend strips for all four regions, consistent with the downward sloping pattern of risk premia.

BBK document that U.S. dividend strips exhibit excess volatility, that is, dividend futures prices move more than their corresponding dividend realizations. In Figure 3 we plot for each of the four regions the 2-year dividend futures price against the corresponding annual dividend realization two years later, that is, we plot the dividend realization in year $t+2$ at time $t$ in the graph so that the eventual dividend realization for the contract is lined 

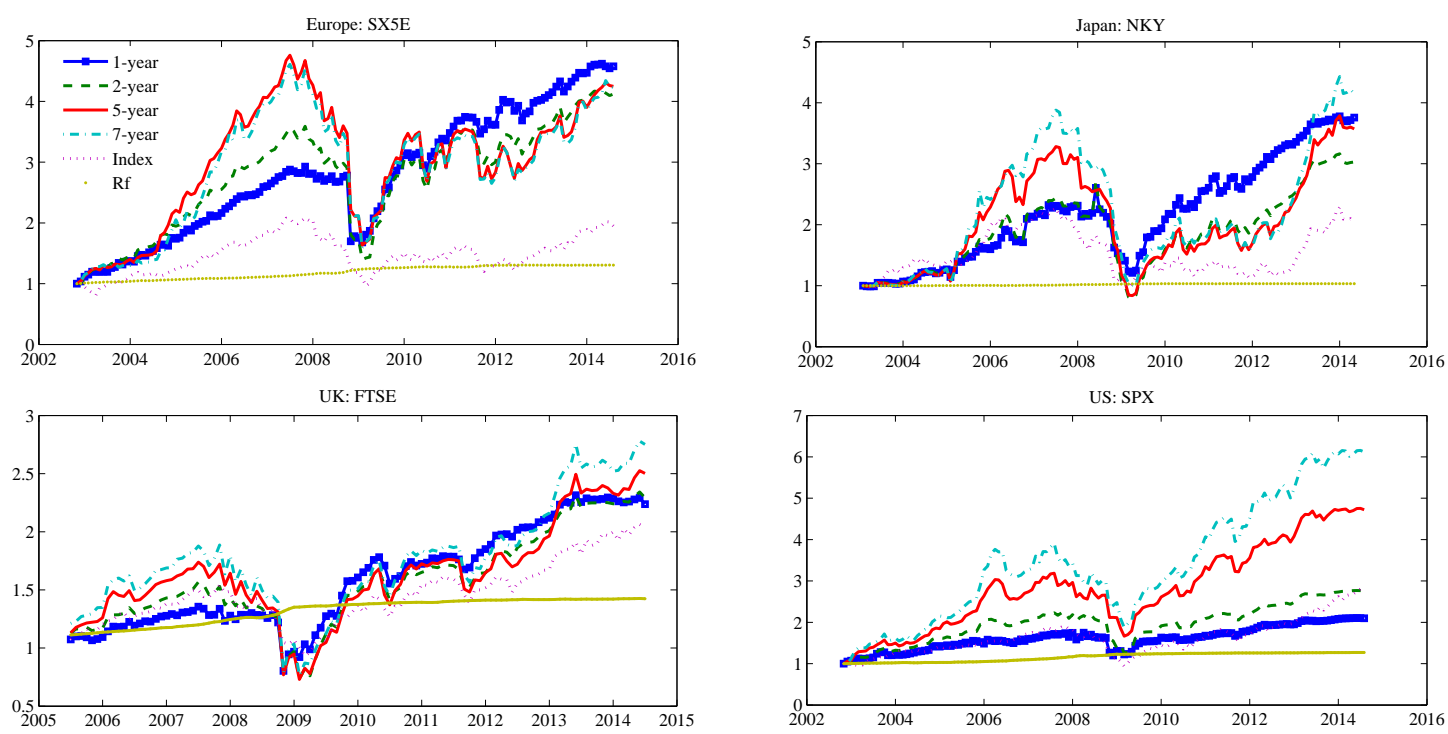

Figure 2: Cumulative Performance Dividend Spot Contracts

The four panels in the figure display the cumulative performance of constant maturity dividend spot contracts (i.e. dividend futures contract returns plus the corresponding zero-coupon bond return) with maturities of 1,2,5 and 7 years between 2002 and 2014 for the Europe and the US, between 2003 and 2014 for Japan and between 2006 and 2014 for the UK. As a comparison we also plot the cumulative performance of the index as well as the performance of the risk free rate as proxied for by the constant maturity 1-year bond return.

up with the dividend futures price at time $t$. The graph shows that for all four regions, the dividend futures prices are more volatile than their corresponding dividend realization, illustrating that dividend futures exhibit excess volatility. Also, the graph shows that on average the dividend futures price is substantially lower than the corresponding realization, illustrating once again that short-term dividend risk carries a large risk premium. The graph also illustrates that during the crisis, a long position in dividend futures experienced large losses.

In Figure 4, we summarize the CAPM betas for each region for each of the 7 maturities, as well as for the strategy that goes long the index and short the 10-year bond. The graph shows a consistent pattern across the four regions. CAPM betas for short-maturity dividend futures contracts are low and around 0.5 and for longer maturities, these CAPM betas gradually converge to a CAPM beta of 1 . Note that the strategy that goes long the index and short the 10-year bond has a CAPM beta slightly higher than 1 for all four regions over this sample period.

Finally, we use the dividend futures and spot returns to test a variety of hypotheses regarding the slope of the term structure of the equity risk premium. The results are summarized in Table 2. We test whether various portfolios of dividend futures and spot returns 


\begin{tabular}{|c|c|c|c|c|c|c|c|c|}
\hline Maturity in years & 1 & 2 & 3 & 4 & 5 & 6 & 7 & Index - 10y bonds \\
\hline \multicolumn{9}{|c|}{ Europe: SX5E (Nov 2002 - Jul 2014) } \\
\hline mean & 0.0101 & 0.0097 & 0.0085 & 0.0082 & 0.0085 & 0.0079 & 0.0075 & -0.0004 \\
\hline stdev & 0.0458 & 0.0624 & 0.0689 & 0.0708 & 0.0713 & 0.0719 & 0.0721 & 0.0608 \\
\hline Sharpe & 0.2214 & 0.1556 & 0.1239 & 0.1152 & 0.1200 & 0.1096 & 0.1046 & -0.0064 \\
\hline \multicolumn{9}{|c|}{ Japan: NKY (Jan 2003 - Jul 2014) } \\
\hline mean & 0.0112 & 0.0107 & 0.0107 & 0.0115 & 0.0115 & 0.0119 & 0.0124 & 0.0055 \\
\hline stdev & 0.0521 & 0.0701 & 0.0738 & 0.0772 & 0.0771 & 0.0809 & 0.0821 & 0.0608 \\
\hline Sharpe & 0.2160 & 0.1526 & 0.1450 & 0.1489 & 0.1490 & 0.1473 & 0.1511 & 0.0902 \\
\hline \multicolumn{9}{|c|}{ UK: FTSE (Jan 2005 - Jul 2014) } \\
\hline mean & 0.0061 & 0.0065 & 0.0062 & 0.0063 & 0.0065 & 0.0067 & 0.0072 & 0.0015 \\
\hline stdev & 0.0499 & 0.0610 & 0.0675 & 0.0703 & 0.0729 & 0.0746 & 0.0775 & 0.0505 \\
\hline Sharpe & 0.1222 & 0.1059 & 0.0916 & 0.0893 & 0.0894 & 0.0900 & 0.0933 & 0.0289 \\
\hline \multicolumn{9}{|c|}{ US: SPX (Nov 2002 - Jul 2014) } \\
\hline mean & 0.0041 & 0.0059 & 0.0067 & 0.0072 & 0.0084 & 0.0090 & 0.0095 & 0.0020 \\
\hline stdev & 0.0337 & 0.0405 & 0.0482 & 0.0496 & 0.0513 & 0.0544 & 0.0559 & 0.0553 \\
\hline Sharpe & 0.1224 & 0.1464 & 0.1390 & 0.1453 & 0.1633 & 0.1645 & 0.1707 & 0.0368 \\
\hline
\end{tabular}

Table 1: Properties of Dividend Strip Returns

We summarize the average return, standard deviation and Sharpe ratio of dividend strip returns across maturities of 1-7 years, and regions: Europe, Japan, the United Kingdom, and the United States.

outperform their corresponding index returns. The table shows that for the Eurostoxx 50 index, we can reject the null hypothesis that average dividend futures returns are lower or equal than the corresponding average index return. For spot returns, we can also reject the null that the 1-year and 2-year average dividend strip returns are lower or equal than those of the index. This implies that, despite the fact that the bond risk premium is increasing with maturity, we still find that the average total return on short-term dividend strips is statistically significantly higher than the total return of the index.

In terms of statistical significance, the results for the other indices individually are weaker than those of the index. As argued before, because dividend strips and futures returns are risky, we have relatively little power to reject over the short data sample that we have. However, if we pool data across the first five maturities and across the four regions, we still find strong evidence that the term structure of the equity risk premium is downward sloping, with a p-value of 0.021 for dividend futures returns and 0.056 for dividend spot returns. 

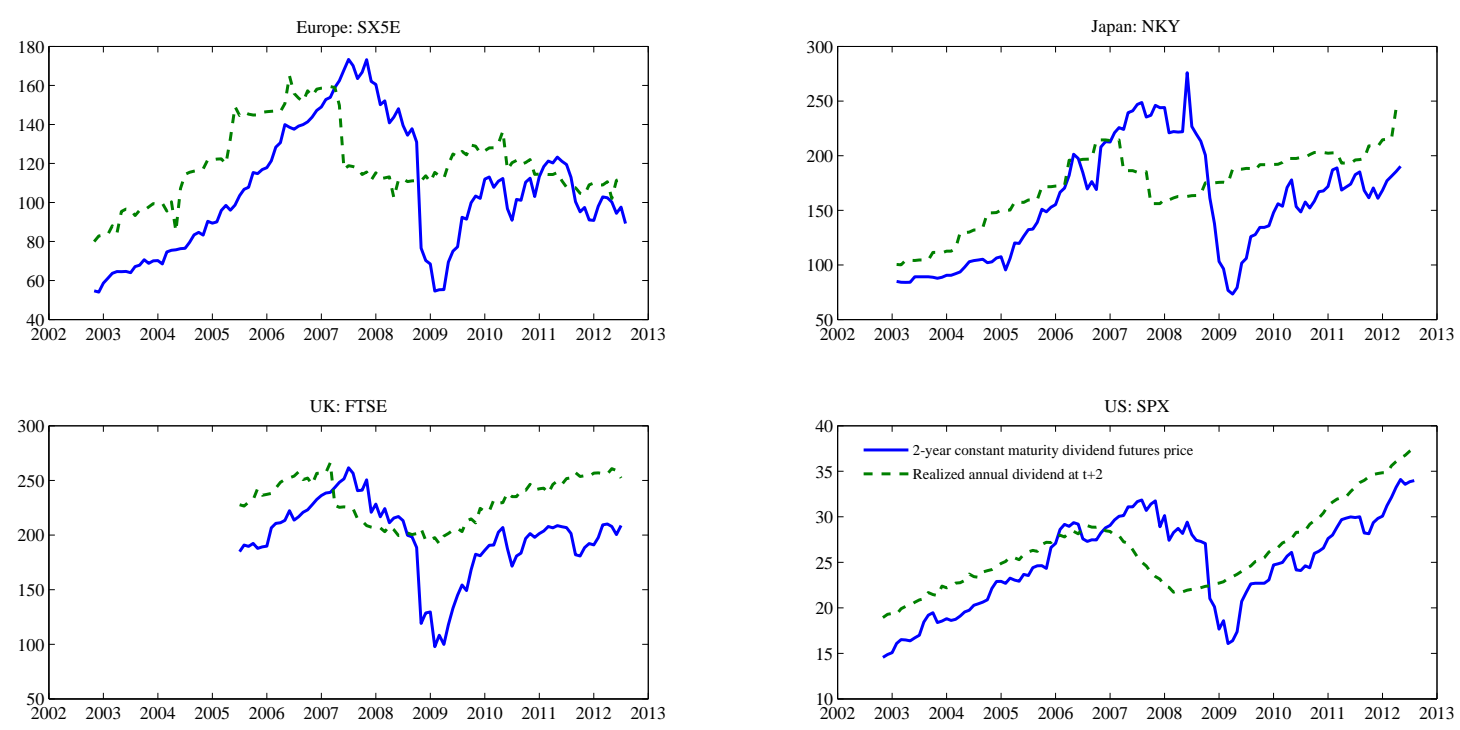

Figure 3: Excess Volatility

The four panels in the figure display the 2-year constant maturity dividend futures price and plots it against the realized annual dividend two years later for all four regions.

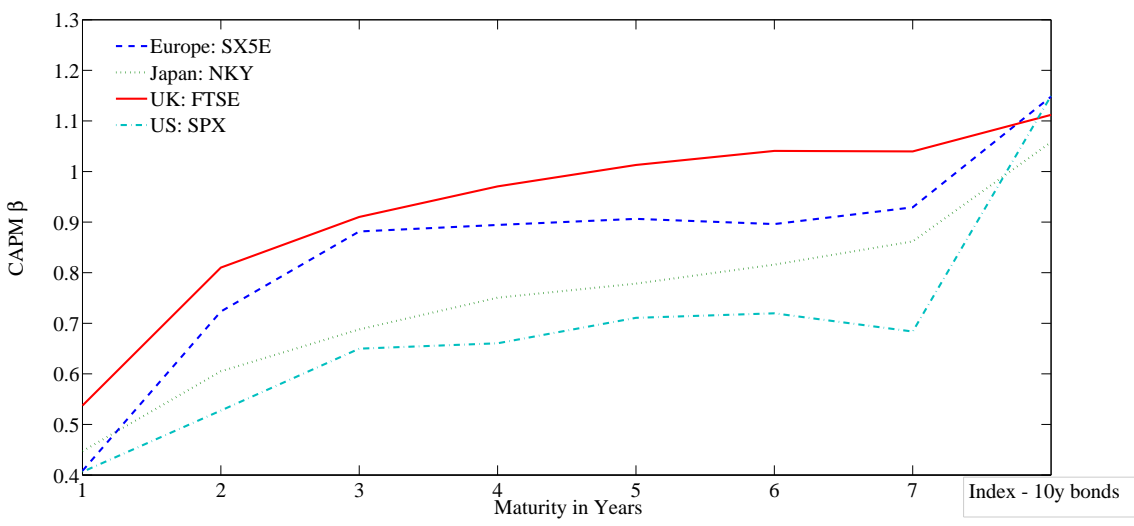

\section{Figure 4: CAPM Betas}

The graph plots the uncondtional CAPM betas for dividend futures for all 7 maturities, as well as for the strategy that goes long in the index and short in the 10-year bond. Each line represents one of the four regions. 


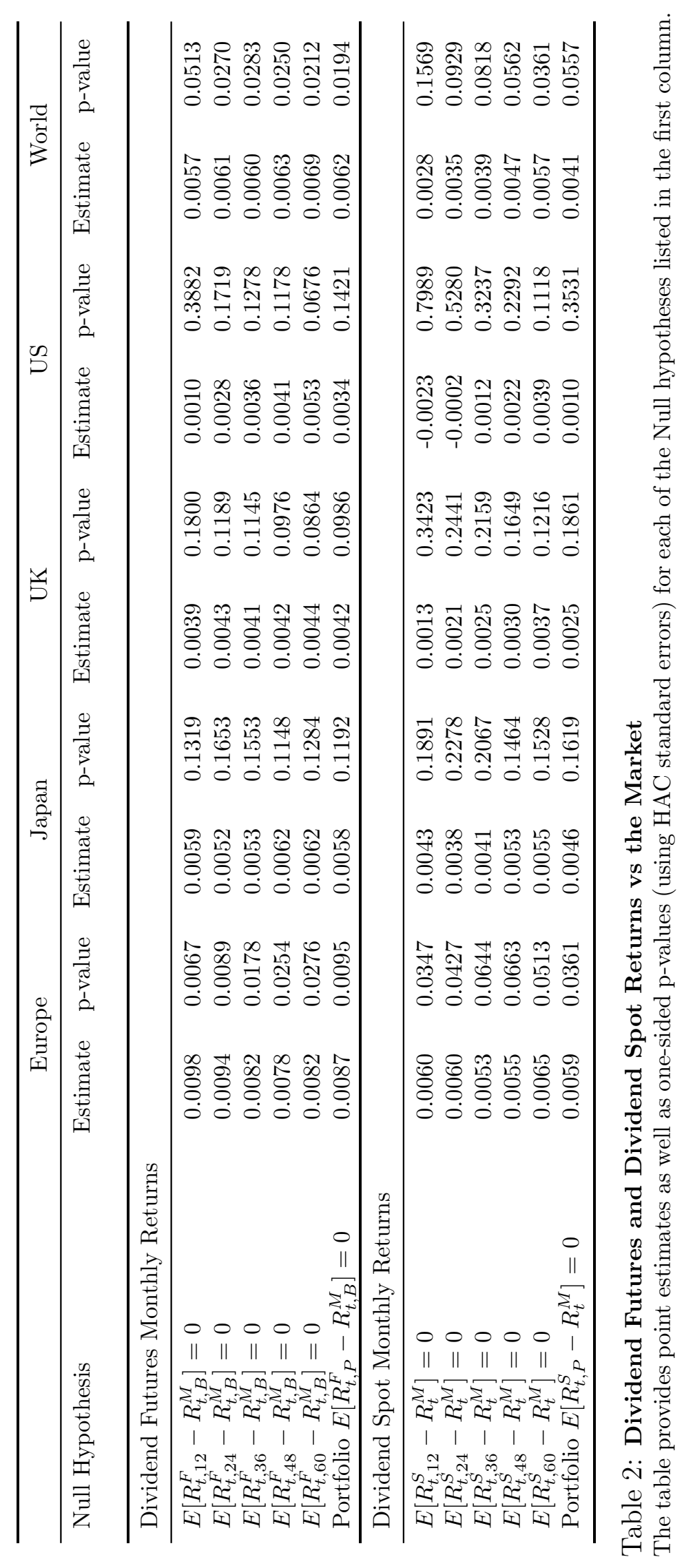




\section{Macro-Finance Models and the Term Structure of Dividend Strips}

In this section we summarize the theoretical implications of leading macro-finance models for dividend strip returns. As a point of reference, we start with the canonical consumption CAPM.

\subsection{Consumption CAPM}

We start from the most basic consumption CAPM as proposed by Lucas (1978), where the preferences of the representative agent are

$$
\max \sum_{s=0}^{\infty} E_{t}\left(\beta^{s} u\left(C_{t+s}\right)\right),
$$

where $u(x)=x^{1-\gamma} /(1-\gamma)$. Consumption growth is assumed to be identically and independently distributed (i.i.d.) and given by:

$$
\Delta c_{t+1}=\mu_{c}+\sigma_{c} \epsilon_{c, t+1}
$$

Dividends are a levered claim on consumption, $D_{t}=C_{t}^{\lambda}$, where $\lambda>1$. The price of dividend strips in this case is given by:

$$
P_{t, n}=E_{t}\left(M_{t: t+n} D_{t+n}\right)=\phi_{n} D_{t}
$$

where $M_{t: t+n}=\beta^{n}\left(C_{t+n} / C_{t}\right)^{-\gamma}$ denotes the $n$-period stochastic discount factor and $\phi_{n}$ a constant that depends on maturity. The expected geometric return for strips of all maturities is constant.

However, the consumption CAPM fails in important dimensions, such as the equity risk premium, the dynamics of the risk-free rate, and excess volatility. To address these shortcomings, three key models have been proposed that are successful at reconciling these puzzles. We briefly discuss each of these models and summarize their predictions for risk premia, Sharpe ratios, and volatilities of dividend strips. More detailed calculations can be found in BBK.

\subsection{External Habit Formation: Campbell and Cochrane (1999)}

Campbell and Cochrane (1999) modify the preferences in (11) to external habit formation preferences. As consumption falls, the ratio of marginal utility in period $t$ to marginal utility in period $t-1$ increases, and risk premia rise accordingly. However, long-term dividend strips 
are more sensitive to discount rate shocks and risk premia. Sharpe ratios, and volatilities are therefore upward-sloping with maturity, keeping the holding period fixed.

In the model, the stochastic discount factor is given by:

$$
M_{t+1}=\delta G^{-\gamma} e^{-\gamma\left(s_{t+1}-s_{t}+v_{t+1}\right)},
$$

where $G$ represents expected consumption growth, $\gamma$ is the curvature parameter, $v_{t+1}$ is unexpected consumption growth, and $s_{t}$ is the log consumption surplus ratio whose dynamics are given by:

$$
s_{t+1}=(1-\phi) \bar{s}+\phi s_{t}+\lambda\left(s_{t}\right) v_{t+1} .
$$

$\lambda\left(s_{t}\right)$ is the sensitivity function that is chosen such that the risk free rate is constant, see (Campbell and Cochrane 1999) for further details. Dividend growth in the model is given by:

$$
\Delta d_{t+1}=g+w_{t+1}
$$

We solve the model using the solution method described in (Wachter 2005). Let $D_{t}^{(n)}$ denote the price of a dividend at time $t$ that is paid $n$ periods in the future. Let $D_{t+1}$ denote the realized dividend in period $t+1$. The price of the first dividend strip is simply given by:

$$
P_{t, 1}=E_{t}\left(M_{t+1} D_{t+1}\right)=D_{t} E_{t}\left(M_{t+1} \frac{D_{t+1}}{D_{t}}\right)
$$

The following recursion then allows us to compute the remaining dividend strips:

$$
P_{t, n}=E_{t}\left(M_{t+1} P_{t+1, n-1}\right) .
$$

The (spot) return on the $n^{\text {th }}$ dividend strip is given by:

$$
R_{t, n}^{S}=\frac{P_{t, n-1}}{P_{t-1, n}}-1
$$

Because the interest rate is constant in the model, bond returns of all maturities are equal to the risk free rate $R_{f}$ :

$$
R_{t, n}^{B}=R_{f},
$$


and hence, futures returns $R_{t, n}^{F}$ are computed as:

$$
R_{t, n}^{F}=\frac{1+R_{t, n}^{S}}{1+R_{f}}-1
$$

We simulate 1,000 samples of 146 months from the model and compute $R_{t, P}^{F}$ (the return on a equal-weighted portfolio of dividend futures with maturities of $1,2,3,4$, and 5 years), $R_{t, P}^{S}$ (the return on a equal-weighted portfolio of dividend spot contracts with maturities of $1,2,3,4$, and 5 years), $R_{t}^{M}$ (the return on the market portfolio), and $R_{t, B}^{M}$ (the return on the market portfolio minus the 10-year bond return).

Table 3 summarizes the distribution of the sample mean in the model for the above-listed quantities, and compares them with their data point estimates. The table illustrates that in the habit formation model, it is very unlikely that dividend strips match the performance of the index, see also Lettau and Wachter (2007). Only in $1.3 \%$ of the simulated samples do dividend strips beat the index. As a consequence, an outperformance by 44-72 basis points per month, which is what we observe in the data, is a 5-8 standard deviation event.

\begin{tabular}{lrrrrrrrrrrr}
\hline & \multicolumn{4}{c}{ Campbell Cochrane (1999) Habit formation Model } & \multicolumn{4}{c}{ Data } \\
\hline Percentile & 0.5 & 1 & 2.5 & 50 & 97.5 & 99 & 99.5 & Eur & Japan & UK & US \\
\hline$E\left[R_{t, P}^{F}\right]$ & -0.0056 & -0.0047 & -0.004 & 0.0013 & 0.0060 & 0.0071 & 0.0083 & 0.0090 & 0.0111 & 0.0063 & 0.0065 \\
$E\left[R_{t, P}^{F}-R_{t, B}^{M}\right]$ & -0.0066 & -0.0062 & -0.0058 & -0.0031 & -0.0006 & 0.0002 & 0.0004 & 0.0094 & 0.0081 & 0.0049 & 0.0044 \\
$E\left[R_{t, P}^{S}-R_{t}^{M}\right]$ & -0.0066 & -0.0062 & -0.0058 & -0.0031 & -0.0006 & 0.0002 & 0.0004 & 0.0060 & 0.0064 & 0.0026 & 0.0011 \\
\hline
\end{tabular}

Table 3: The Simulated Average Return of Dividend Strips in the Habit Formation Model The table provides the percentiles of the simulated mean of a portfolio of dividend futures and dividend spot returns (in absolute terms as well as in excess of the market) in the habit formation model, where the number of monthly simulations corresponds to the number of observations in the data (146 months). The last four columns report the estimated means in the data for the four geographic regions.

Finally, the habit formation model has predictions for the volatility of equity yields by maturity that we can test. In the data, we find that the volatility of equity yields is strictly decreasing with maturity, with values of 10-18\% for 1-year yields (depending on the region), and values of $3-6 \%$ for 7 -year yields.

In Figure 5, we plot the volatility across the four regions by maturity, and contrast these values with the predicted values of the habit formation model. As before, we simulate the model 1000 times for 146 months, and for each simulation we compute the volatility of equity yields by maturity. The graph shows the median volatility (solid line) by maturity across the 1000 simulations, as well as the $95 \%$ confidence bound (the dotted line). As is clear from the figure, the volatility of equity yields is much too low in the external habit model as short-term risk premia are low and virtually constant. This is a powerful test of the model as 
volatilities can be measured more precisely than average returns. Moreover, in the data the volatility of equity yields declines with maturity, while it is upward-sloping in the external habit model.

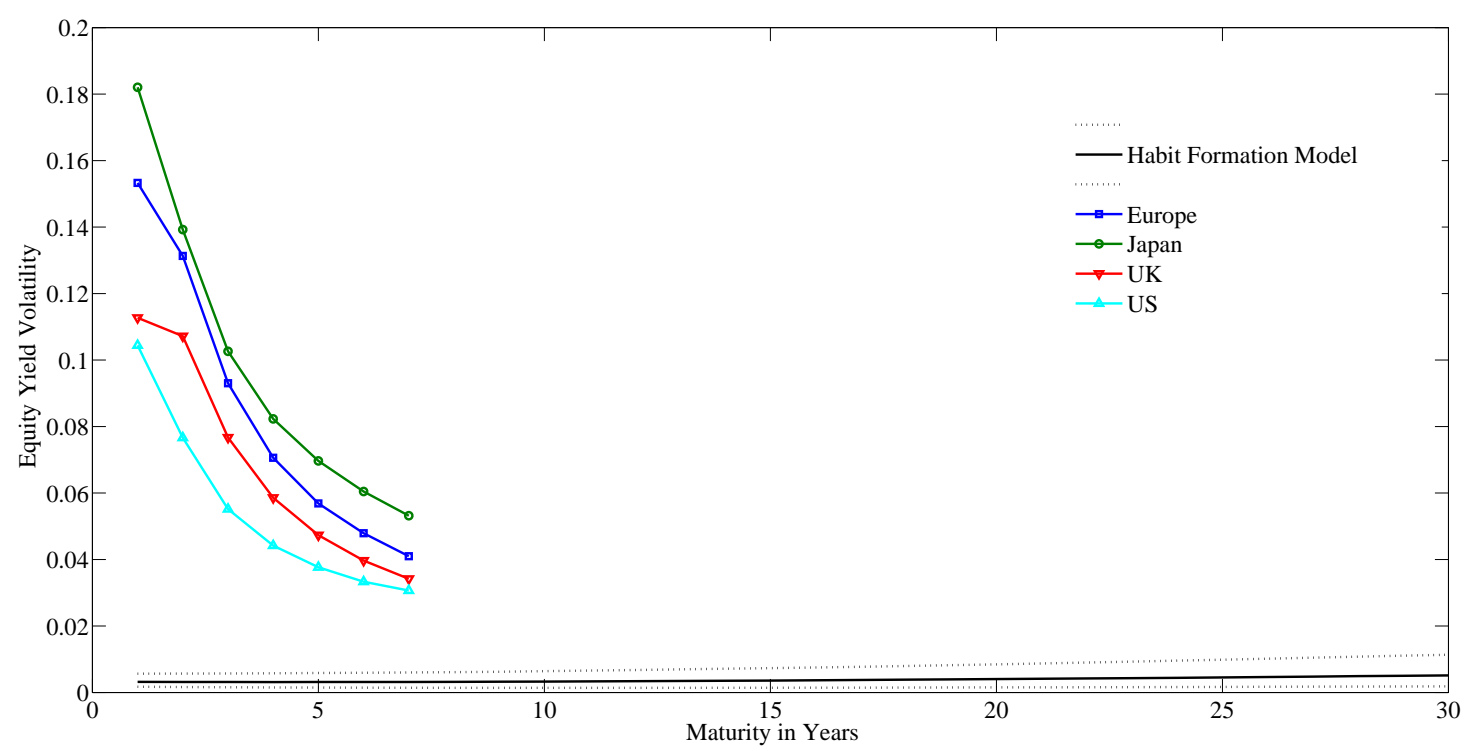

Figure 5: Equity Yield Volatility

The graph shows the estimated yield volatility in the data and contrasts it with the estimated yield volatility in the simulated Campbell and Cochrane (1999) habit formation model. We simulate the model 1000 times for 146 months, and for each simulation compute the volatility of the equity yields. The solid black line reports the median across 1000 simulations, and the dotted lines indicate the $95 \%$ confidence bound.

\subsection{Long-run Consumption Risks: Bansal and Yaron (2004)}

Bansal and Yaron (2004) make two modifications to the standard consumption CAPM. First, they modify the time additive preferences to recursive Epstein and Zin (1989) preferences, which introduces a preference for early resolution of uncertainty. ${ }^{6}$ Second, they introduce a small, but highly persistent, predictable component in consumption growth, which modifies equation (12). Also, they allow for heteroscedasticity in consumption growth, which generates time variation in risk premia. In line with the external habit model, longer-term dividend strips are more sensitive to the predictable component in consumption growth and to changes in the volatility of consumption growth. As a result, risk premia, Sharpe ratios, and volatilities are therefore upward-sloping with maturity, keeping the holding period

\footnotetext{
${ }^{6}$ See Epstein, Farhi, and Stralezcki (2014) for a detailed discussion of the timing premium in the long-run risks model.
} 
fixed. ${ }^{7}$

\subsection{Variable Rare Disasters: Gabaix (2012) and Wachter (2013)}

Gabaix (2012) extends the rare disaster model of Reitz (1988) to allow for a persistent, time-varying probability of disasters. Gabaix (2012) assumes that the representative agent still has power utility preferences and, as a result, expected returns do not depend on the maturity as in the standard consumption CAPM. However, volatilities of returns are upward sloping with maturity, while Sharpe ratios are downward-sloping with maturity. Wachter (2013) extends Gabaix (2012) and uses Epstein and Zin preferences instead. In this case, expected returns are upward sloping as well as recursive preferences price the low-frequency variation in the disaster probability, which is more important for long-horizon claims.

\section{The Term Structure of Sharpe Ratios in Other Asset Classes}

In this section, we summarize the evidence in other asset classes, such as nominal bonds, corporate bonds, volatility, and housing.

\subsection{Nominal Bonds}

First, we analyze the properties of returns on nominal Treasury bonds by maturity. We use the CRSP Treasury bond portfolios for which there are six maturity buckets from January 1952 until December 2013, which correspond to 1-12 months, 13-24 months, 25-36 months, 37-48 months, 49-60 months, and 61-120 months, respectively. ${ }^{8}$

\begin{tabular}{lllllll}
\hline & $1-12$ & $13-24$ & $25-36$ & $37-48$ & $49-60$ & $61-120$ \\
\hline Average excess return & $0.58 \%$ & $1.03 \%$ & $1.36 \%$ & $1.56 \%$ & $1.56 \%$ & $1.83 \%$ \\
Standard deviation & $0.80 \%$ & $2.05 \%$ & $3.13 \%$ & $3.95 \%$ & $4.67 \%$ & $5.76 \%$ \\
Sharpe ratio & 0.73 & 0.50 & 0.43 & 0.40 & 0.33 & 0.32 \\
\hline
\end{tabular}

Table 4: We summarize the annualized average excess return, standard deviation and Sharpe ratios of nominal Treasury bond returns. The maturities (in months) are summarized in the first row of the table. The sample period is from January 1952 until December 2013.

The results are presented in Table 4 . We find that the average returns and standard deviations increase with maturity. However, this is to some extent a mechanical effect as a

\footnotetext{
${ }^{7}$ In terms of properties of dividend strip returns across maturities, the model with preference shocks proposed by Albuquerque, Eichenbaum, and Rebelo (2014) behaves similarly to a long-run risks model.

${ }^{8}$ There is a return series for bonds with maturities longer than 10 years, but these returns are sometimes missing.
} 

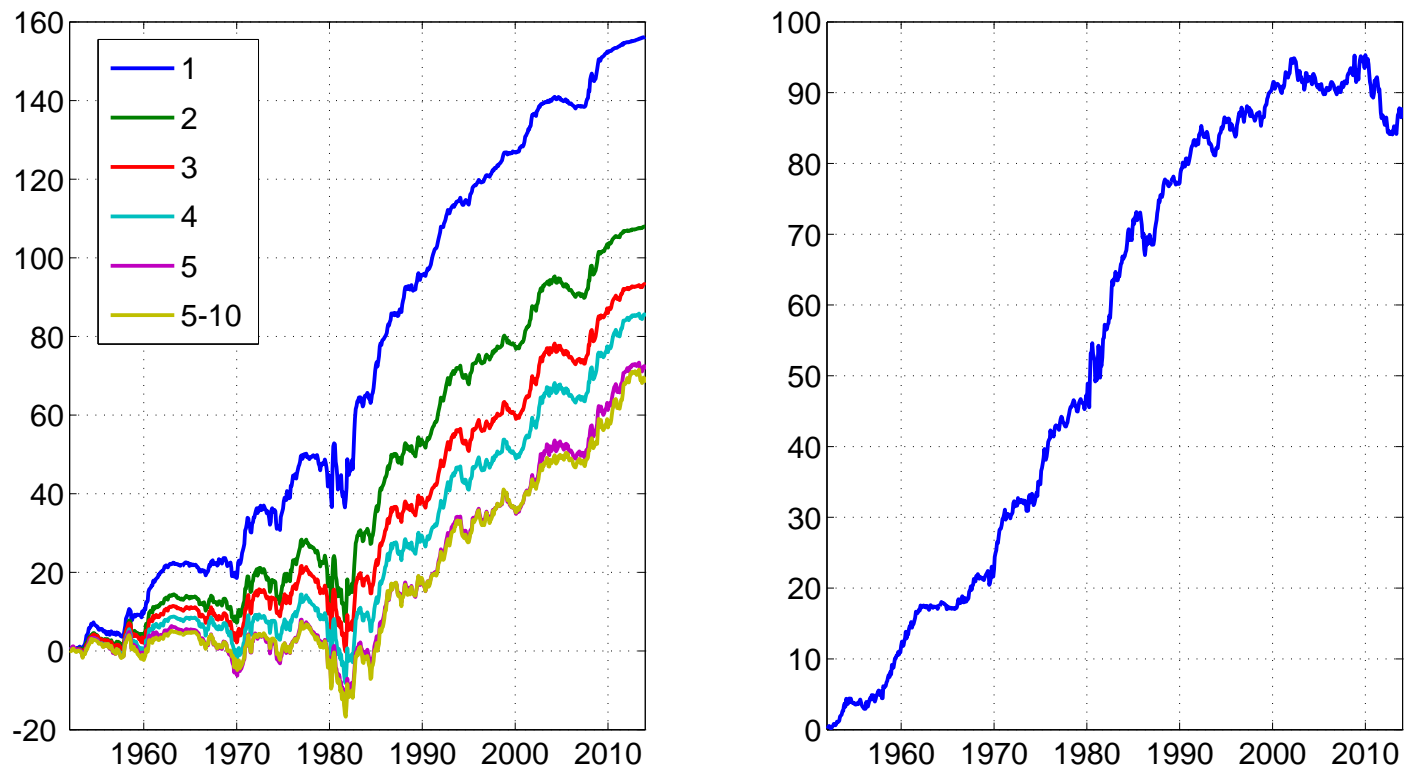

Figure 6: The left panel displays the cumulative excess returns for various maturities. All strategies are scaled by their full-sample standard deviations. The right panel displays the returns to a strategy that buys the shortest-maturity bonds and shorts the longest-maturity bonds. The sample period is from January 1952 until December 2013.

result of the longer duration of long-term bonds. The Sharpe ratio corrects for differences in duration.

The Sharpe ratios are strongly downward sloping in maturity, consistent with Duffee (2012). The short-term Sharpe ratios are as high as 0.73, while the long-term Sharpe ratios decline to 0.32. This finding also relates to the observation by Hansen and Jagannathan (1991) whose figures point to an attractive risk-return trade-off for short-maturity bonds. ${ }^{9}$

In Figure 6, the left panel, we plot the cumulative excess returns on the various Treasury portfolios. To make the portfolios comparable, we scale them by their volatilities measured over the entire sample period. The right panel displays the returns to a strategy that buys the shortest-maturity bonds and shorts the longest-maturity bonds, where both portfolios are again scaled to have the same volatility, which makes the overall portfolio effectively duration neutral.

\footnotetext{
${ }^{9}$ Luttmer (1996) tries to rationalize these findings with trading frictions. However, we show that the downward-sloping pattern in Sharpe ratios hold across the entire maturity spectrum and in four asset classes.
} 


\subsection{Corporate Bonds}

Next, we turn to corporate bond returns. We use the Barclays corporate bond indices for "Intermediate" (average duration about 5 years) and "Long-term" (average duration about 10 years) maturities. In terms of credit quality, we consider AAA, AA, A, and BAA ratings. The sample period is January 1973 to August 2014.

\begin{tabular}{lllll}
\hline Intermediate & AAA & AA & A & BAA \\
\hline Average excess return & $2.38 \%$ & $2.53 \%$ & $2.76 \%$ & $3.44 \%$ \\
Standard deviation & $5.02 \%$ & $4.99 \%$ & $5.28 \%$ & $5.48 \%$ \\
Sharpe ratio & 0.47 & 0.51 & 0.52 & 0.63 \\
& & & & \\
Long term & AAA & AA & A & BAA \\
\hline Average excess return & $3.12 \%$ & $3.80 \%$ & $3.75 \%$ & $4.60 \%$ \\
Standard deviation & $10.45 \%$ & $9.74 \%$ & $9.67 \%$ & $9.82 \%$ \\
Sharpe ratio & 0.30 & 0.39 & 0.39 & 0.47 \\
\hline
\end{tabular}

Table 5: We summarize the annualized average excess return, standard deviation and Sharpe ratios of corporate bond returns. The credit quality is summarized in the first row of each panel. The top panel displays the results for the intermediate maturity (duration around 5 years) and the bottom panel for the long-term maturity (duration around 10 years). The sample period is from January 1973 until August 2014.

The results are presented in Table 5. We find, for each level of credit quality, that average returns and standard deviations increase with maturity. However, the Sharpe ratios decline by around $25 \%$ when we move from intermediate to long-term bonds. In Figure 7 , we plot the cumulative excess returns to a strategy that buys intermediate-term corporate bonds of a given credit quality and shorts long-term corporate bonds of the same credit quality. The long and short portfolios are scaled to have the same volatility.

The results for corporate bonds resonate with recent findings in the literature on credit default swaps (CDS), where Palhares (2012) documents that short-maturity CDS contracts have much higher Sharpe ratios than long-maturity CDS contracts.

\subsection{Variance Risk}

The next asset class that we consider is volatility. We use a portfolio of index options that is particularly exposed to variance risk by writing a put and a call option with a strike price as close as possible to the current stock price, that is, a straddle strategy. We consider five maturity groups: 30-90 days, 90-180 days, 180-270 days, 270-360 days, and all options with a maturity longer than 360 days. We focus on S\&P500 index options, which is among the most liquid option markets. 


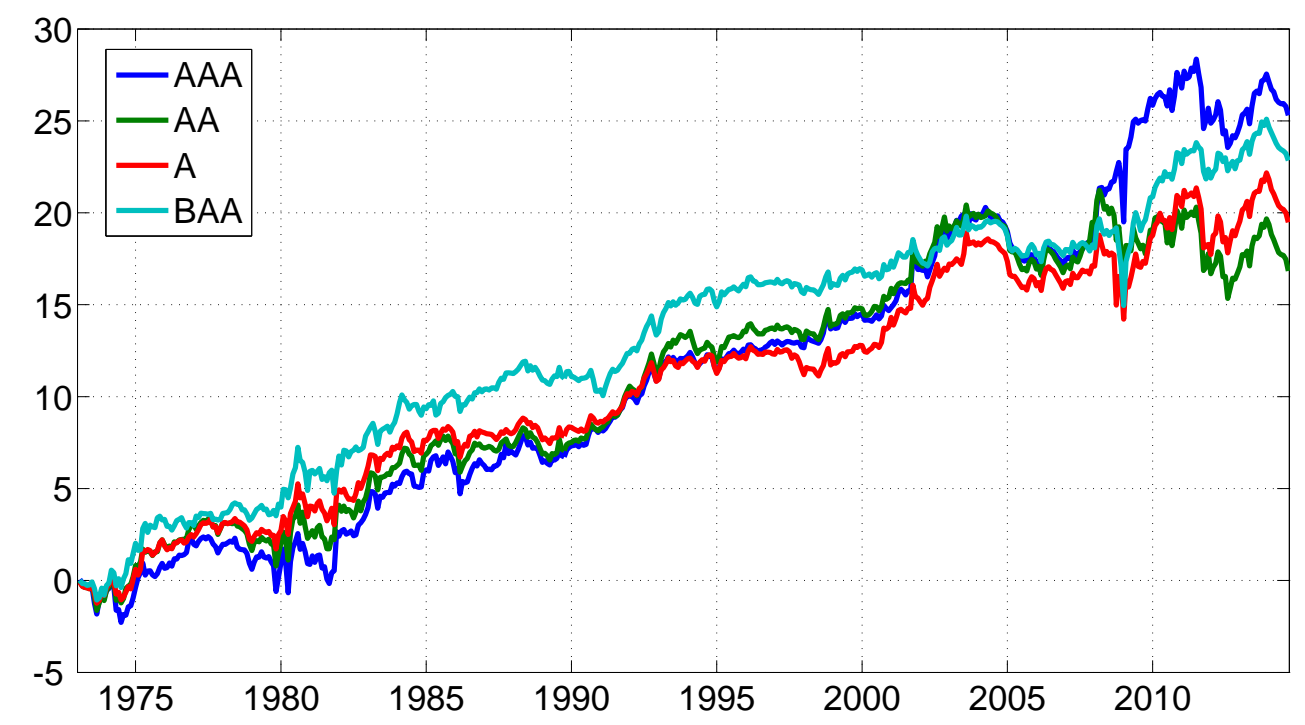

Figure 7: We plot the cumulative excess returns to a strategy that buys intermediate-term corporate bonds of a given credit quality and shorts long-term corporate bonds of the same credit quality. The long and short portfolios are scaled to have the same volatility. The sample period is from January 1973 until August 2014.

\begin{tabular}{llllll}
\hline \hline Maturity in days: & $30-90$ & $90-180$ & $180-270$ & $270-360$ & $>360$ \\
\hline \hline Average excess return & $185 \%$ & $61 \%$ & $30 \%$ & $17 \%$ & $8 \%$ \\
Standard deviation & $114 \%$ & $47 \%$ & $34 \%$ & $29 \%$ & $27 \%$ \\
Sharpe ratio & 1.62 & 1.30 & 0.89 & 0.58 & 0.30 \\
\hline
\end{tabular}

Table 6: We summarize the annualized average excess return, standard deviation and Sharpe ratios of short straddle returns. The sample period is from February 1996 until August 2013.

The results for a (short) straddle position are reported in Table 6. We find, consistent with the other asset classes, that Sharpe ratios decline with maturity. What is particularly interesting in case of options is that the Sharpe ratios are large and that the Sharpe ratios decline more rapidly in comparison to the other asset classes. Sharpe ratios are 1.62 for the short-maturity contracts and decline to 0.30 for contracts with a maturity longer than a year. In Figure 8, we plot the cumulative excess return of shorting the short-term straddle and buying a long-term straddle. The long and short portfolios are scaled to have the same volatility.

Our findings are consistent with Ait-Sahalia, Karaman, and Mancini (2014), Dew-Becker, Giglio, Le, and Rodriguez (2014), and Andries, Eisenbach, Schmalz, and Wang (2015). DewBecker, Giglio, Le, and Rodriguez (2014) show that the Sharpe ratios of a short position in 


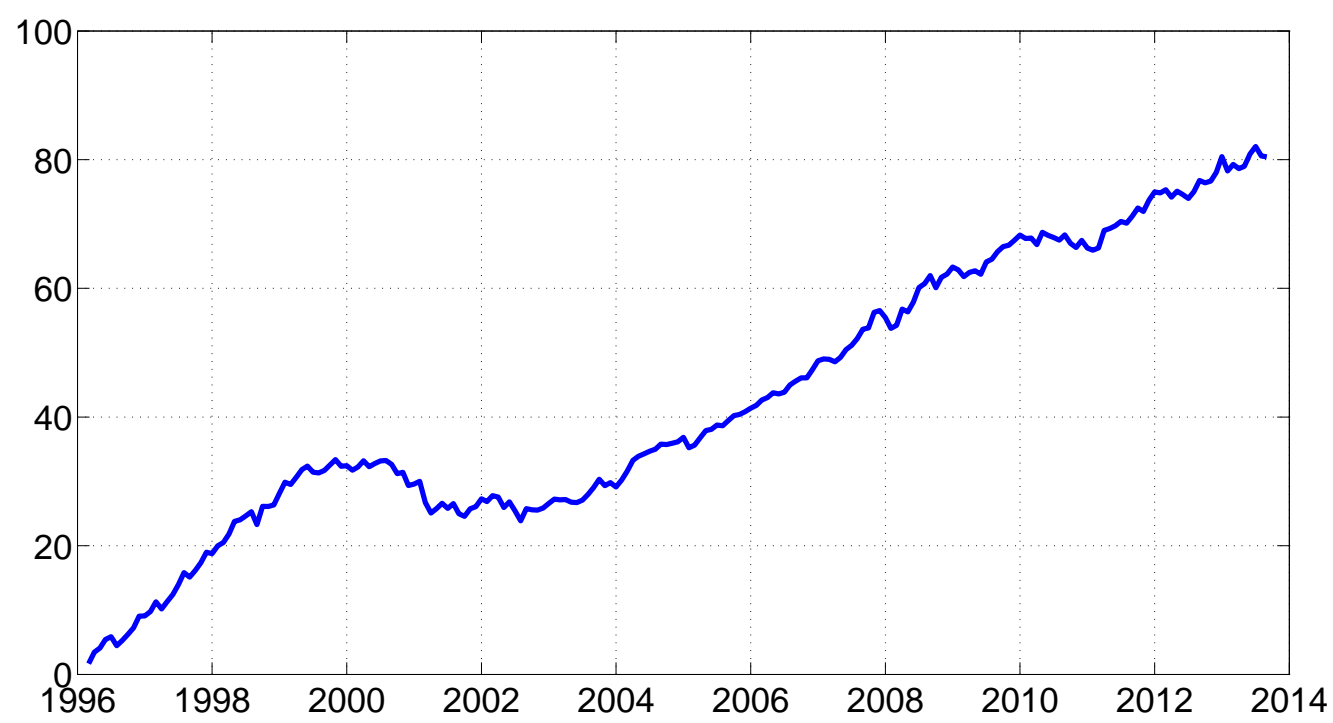

Figure 8: We plot the cumulative excess return of shorting the short-term straddle and buying a long-term straddle. The long and short portfolios are scaled to have the same volatility. The sample period is from February 1996 until August 2013.

variance swaps declines rapidly with maturity and is insignificant for maturities longer than two months. Andries, Eisenbach, Schmalz, and Wang (2015) focus on the Sharpe ratios of at-the-money index straddles instead, which is closely related to the results that we report in Table 6 .

\subsection{Housing}

The final market that we discuss is housing. Recently, Giglio, Maggiori, and Stroebel (2014) study the differences in asset prices of leaseholds and freeholds in the United Kingdom and Singapore. The difference between leasehold and freehold prices reflects the present value of perpetual rental income starting at leasehold expiry.

Under assumptions about future rent growth, one can back out the long-term discount rate to reconcile price differences between leaseholds and freeholds (see also Badarinza and Ramadorai (2014)). Giglio, Maggiori, and Stroebel (2014) find that long-run discount rates must be very low. As it is hard to compute returns directly, we cannot compare Sharpe ratios across maturities, which is the robust finding that we document across asset classes. 


\section{New Theories About the Term Structure of Discount Rates}

In this section, we summarize an emerging literature of macro-finance models that provide potential explanations for some of the facts that we discussed in earlier sections. We start with homogenous agent models and focus on models that adjust either preferences or the technology process. Next, we discuss models that depart from the representative agent models by introducing interesting form of heterogeneity. We conclude with a discussion explanations based on market microstructure noise or taxation.

\subsection{Alternative Models of Preferences}

Eisenbach and Schmalz (2014) propose to modify preferences so that the representative agent is more risk averse with respect to imminent risks than distant risks. Such preferences find support in a series of lab experiments. Eisenbach and Schmalz (2014) develop a 2-period model, which is extended to an infinite-horizon economy by Andries, Eisenbach, and Schmalz (2014). In terms of technology, Andries, Eisenbach, and Schmalz (2014) follow the long-run risks literature and allow for a slow-moving predictable component, as well as stochastic volatility, in consumption growth.

Andries, Eisenbach, and Schmalz (2014) find that these preferences generate a decreasing term structure of risk premia if and only if volatility is stochastic. The model therefore implies that the term structure of risk premia for dividend strips is driven by a downward-sloping term structure of the price of volatility risk.

Andries (2014) studies a model in which the agent has loss-aversion preferences. This induces important nonlinearities in expected excess returns as a function of the exposure to the consumption shocks. The risk premium is higher for assets that are relatively "safe" (with low exposure to the consumption shocks) than for assets that are relatively "risky" (with large exposure to the consumption shocks). This feature of loss aversion generates a downward slopping term structure of Sharpe ratios. Curatola (2014) combines a model of loss aversion and habit formation. The model produces an upward-sloping real term structure, but risk premia and volatilities on dividend strips are downward-sloping in maturity. Intuitively, long-horizon dividend strips have higher expected payoffs that are further from the kink. As a result, the effective risk aversion is lower. Berrada, Detemple, and Rindisbacher (2013) consider a regime-switching model where the preferences change with the regimes. The agent does not directly observe the regimes and needs to learn about the state of the economy. The model is able to reproduce the high volatility of short term dividend strip prices and the first and second moments of bond yields. 
Building on the model with demand shocks as developed by Albuquerque, Eichenbaum, and Rebelo (2014), Marfe (2014b) introduces demand shocks that are correlated with endowment shocks and that cannot be perfectly observed by the agent. Otherwise, the model resembles a homoscedastic long-run risks model. Marfe (2014b) derives general conditions on the properties of demand shocks and preference parameters to ensure the correct slopes of the term structures of equity yields and real bond yields.

Andries, Eisenbach, and Schmalz (2014), Curatola (2014), Marfe (2014b), and Berrada, Detemple, and Rindisbacher (2013) are the only papers that we are aware of that study risk premia for multiple term structures at the same time.

\subsection{Alternative Models of Technology}

A second class of models modifies the technology process for consumption and dividends. Nakamura, Steinsson, Barro, and Ursua (2013) and Hasler and Marfe (2015) extend the disaster model as developed by Barro (2006) to allow for recoveries following a disaster (see also Gourio (2008)). The model is successful in generating risk premia for dividend strips that decline with maturity.

The model's intuition can be illustrated with a simple example in which consumption and dividends at time $t+1$ falls if a disaster strikes in that period, but fully recovers the subsequent period. If an agent prices dividend strips at time $t$, then the 1 -period dividend strip is fully exposed to the $t+1$ disaster risk, but the $2-$ period dividend strip is not. As a result, the risk premium on the 2 -period dividend strip is higher.

Belo, Collin-Dufresne, and Goldstein (2014) and Marfe (2014a) also propose to modify the dynamics of the dividend process. Belo, Collin-Dufresne, and Goldstein (2014) model the earnings process and assume, in addition, that leverage ratios are stationary. In the model, shareholders are being forced to divest (invest) when leverage is low (high), which shifts longhorizon growth risk of earnings to short-horizon dividends. As a result, dividends are more volatile than earnings over short horizons, but they are equally volatile over long horizons as dividends and earnings are cointegrated. In this model, the consumption dynamics and preferences, and hence the stochastic discount factor, are unaffected. The main modification is the exposure of dividends to shocks to the stochastic discount factor at various horizons.

Belo, Collin-Dufresne, and Goldstein (2014) illustrate the mechanism in the context of the long-run risks model and the external habit model. They show that the calibrated model can reproduce the low market betas of short-maturity strips, and hence the high alphas, as well as the downward-sloping Sharpe ratios. A key implication is that leverage ratios 
forecast long-term dividend growth rates, for which Belo, Collin-Dufresne, and Goldstein (2014) provide some evidence at very long horizons.

Marfe (2014a) proposes a similar mechanism, but instead of assuming stationary leverage ratios, he assumes that the labor share is stationary. The implications for dividends strips are very similar, although now the labor share has to forecast future dividend growth. Marfe (2014a) provides also some support in favor of this mechanism as well. He also concludes that the dividend share conveys additional information, beyond financial leverage, concerning the properties of short-run dividend risk.

Ai, Croce, Diercks, and Li (2012) consider a production economy with different vintages of capital. They assume that newer vintages of capital are less exposed to productivity shocks than older vintages. Current dividends are largely produced by older vintages of capital, making short-term dividends riskier than medium-term dividends. In the longrun, all vintages are exposed to productivity shocks in the same way. As a result, the model produces a U-shaped pattern in the term structure of risk premia on dividend strips. Corhay, Kung, and Schmid (2015) study a model with endogenous firm entry and exit, and also find a U-shaped term structure of equity risk premia. In this model, the entry-exit margin drives countercyclical price markups, which increases the volatility and procyclicality of cash flows in the short-run.

\subsection{Alternative Models of Beliefs}

Croce, Lettau, and Ludvigson (2014) develop a model with both short-term and long-run shocks to consumption growth. Instead of assuming that investors have full information about both components, Croce, Lettau, and Ludvigson (2014) consider a representative decision maker who optimizes based on a cash-flow model that is sparse in the sense that it ignores cross-equation restrictions that are difficult (if not impossible) to infer in finite samples. Because of this behavioral assumption about the learning process, assets that have a small exposure to long-run consumption risk, but are highly exposed to short-run (even i.i.d.), consumption risk can command high risk premiums in the bounded rationality limited information case but not under full information. As a result, the term structure of equity risk premia can be downward sloping under the boundedly-rational model, while it is upward sloping under full information as in the long-run risks models.

\subsection{Heterogeneous Agent Models}

The models discussed so far are all representative agent models. Lustig and Nieuwerburgh (2006) are the first to propose a heterogeneous-agents model that produces a downward- 
sloping term structure of dividend strip risk premia. Agents differ in their histories of labor income shocks. In the model, the risk sharing of income shocks is limited by the amount of housing collateral that agents have. Agents face both shocks to the wealth distribution, which fluctuates at the business cycle frequency, and shocks to housing collateral, which fluctuates at lower frequencies. A negative consumption shock temporarily increases discount rates, but it does not affect housing collateral, which governs discount rates in the long run. As a result, the price of consumption strips of longer maturity is insulated from bad consumption shocks today, but they do affect short-maturity consumption strips.

Marfe (2014c) builds on Danthine and Donaldson (2002) and considers a model with two groups of agents, workers and shareholders. Wages do not correspond to the marginal product of labor, but incorporate income insurance that workers exploit within the firm. In turn, the labor-share has counter-cyclical dynamics and, hence, the riskiness of owning capital increases. This increases the riskiness of short-term dividends, which leads to a downward-sloping term structure of dividend strip risk premia.

Favilukis and Lin (2015) introduce sticky wages and a CES production function over capital and labor in an otherwise standard heterogeneous agent production economy. In a frictionless model, wages are too volatile as wages are equal to the marginal product of labor and dividends (and stock returns) are too smooth. Sticky wages reduce the volatility of wages, which turns out to have important implications for a series of asset pricing puzzles, including the term structure of dividend risk premia. The main intuition is that although wages can adjust in the long run, ${ }^{10}$ they can not in the short run. This implies that productivity shocks need to be absorbed by short-term dividends, which makes dividends highly pro-cyclical and gives rise to a downward-sloping term structure of dividend strip risk premia.

\subsection{Asset Pricing Models with an Exogenous Stochastic Discount Factor}

A last class of models that we discuss are not general equilibrium models as they exogenously specify the stochastic discount factor rather than deriving it from preferences. However, such models may give important insights in what a specification of preferences must deliver.

Three key examples are Lettau and Wachter (2007), Lettau and Wachter (2011), and Lynch and Randall (2011). Lettau and Wachter (2007) allow for a temporary component in dividends that receives a high risk price. This risk price fluctuates over time to generate return predictability, but shocks to this risk price are uncorrelated with the stochastic

\footnotetext{
${ }^{10}$ In fact, wages and output are co-integrated in the model, implying that they are equally risky in the long run.
} 
discount factor, which would, for instance, be counterfactual from the perspective of the external habit model. Lettau and Wachter (2007) assume interest rates to be constant. The model matches many of the features that we have documented in this paper, such as risk premia, Sharpe ratios, and CAPM alphas and betas. The volatility of the returns on short-maturity dividend strips also exceeds the volatility of market returns.

Lynch and Randall (2011) develop a related model, but allow the risk price to be correlated with the stochastic discount factor. However, this is only consistent with the evidence on dividend strips, as they show, if the risk price, which Lynch and Randall (2011) interpret as the habit level, is not too persistent. Lynch and Randall (2011) provide interesting micro evidence consistent with the fact that habits are more fast moving than what has been assumed by Campbell and Cochrane (1999).

Lettau and Wachter (2011) extend the model of Lettau and Wachter (2007) by introducing variation in the real interest rate and both expected and unexpected inflation. The key to the model's success is to assume that the real risk-free rate is negatively correlated with fundamentals, which generates an upward sloping real term structure, and a price-of-risk shock that has zero correlation with fundamentals. In the case of nominal bonds, there is an additional effect arising from the negative correlation between fundamentals and expected inflation. This negative correlation implies that nominal bond prices fall when fundamentals are low, leading to a positive inflation risk premium.

\subsection{Risk Prices and Exposures}

Our discussion of the models above makes it clear that there are by now a wide variety of different mechanisms that have been proposed to generate some of the facts related to the term structure of asset prices. However, some models change the technology side of the models, while others rely on preferences or beliefs.

We think that future work can disentangle and test these mechanisms more carefully by decomposing risk premia and Sharpe ratios into risk prices and risk exposures, both in the data and the models, using the tools developed by Hansen and Scheinkman (2009), Hansen, Heaton, and Li (2008), and Borovicka, Hansen, Hendricks, and Scheinkman (2009). Decomposing risk premia and Sharpe ratios in the data into risk prices and exposures provides valuable guidance for the design of future macro-finance models.

\subsection{Market Microstructure, Tax Effects, and the Role of Institutional Investors}

In addition to the novel theories that have been proposed in recent years, there have been some alternative explanations of the findings in BBK that relate to the precise measurement 
of dividend strip prices or to the institutional background of the markets in which these assets are traded.

First, Boguth, Carlson, Fisher, and Simutin (2011) argue that when BBK synthetically replicate dividend strip prices using option prices, small amounts of microstructure noise can be exacerbated when computing returns. Qualitatively, this increases the mean and volatility of measured returns and lowering the estimated CAPM betas.

However, the summary statistics reported in section 2 are computed using dividend futures contracts, and therefore do not rely on synthetic replication. Given that the results using dividend futures contracts all confirm the results in BBK using synthetic replication, measurement error in synthetically replicated dividend strip returns are not the driver of the findings in BBK.

Second, Schulz (2013) argues that taxes could potentially explain the average high return on synthetically replicated strips. Because dividends are taxed at a higher rate than capital gains, and because dividend make up a larger part of the total return for dividend strips relative to the index, this could potentially explain part of the high average return. However, given that dividend futures contracts are not subject to dividend taxation (the dividend is simply used as the underlying to base the contract on, but no actual dividend is received), we should again conclude that the similarity of the results between synthetically replicated strips and dividend futures shows that taxation is not a plausible explanation for the findings in BBK either.

Another explanation that has been suggested is that our findings for dividend strips are the result of large institutions that want to sell dividend exposure, which results in low prices. Although we do not have data to test this explanation directly, we consider this explanation an interesting alternative to the models proposed so far and consistent with a recent literature emphasizing the role of institutions in asset markets. ${ }^{11}$

\section{Concluding Remarks and Broader Economic Implications}

In this paper, we have summarized the basic facts about the term structure of returns in various asset classes and discussed various new theories that have been proposed to explain some of these facts. We conclude this paper by discussing several potential avenues for future research in this area.

First, it would be interesting to extend the large literature on real and nominal term

\footnotetext{
${ }^{11}$ See for instance Dasgupta, Prat, and Verardo (2011), Basak and Pavlova (2013), He and Krisnamurthy (2013), Vayanos and Woolley (2013), Berk and van Binsbergen (2014), and Koijen and Yogo (2015).
} 
structure models ${ }^{12}$ to match equity yields as well. This is particularly interesting given the ongoing debate about the determinants of the time variation in the correlation between bond and stock markets (see for instance Baele, Bekaert, and Inghelbrecht (2010) and Campbell, Sunderam, and Viceira (2013)) and the extent to which stocks are real assets (Katz, Lustig, and Nielsen 2015). Kragt, de Jong, and Driessen (2014) develop a pricing model for equity yields only. In recent work, Ang and Ulrich (2012) propose a joint pricing model for nominal bonds, real bonds, and dividend strips, although no direct data on dividend prices is used in estimation. Recently, Yan (2014) estimates an affine term structure model using data on nominal bonds and dividend strips. By modeling the inflation process, one can study directly whether stocks are a hedge against inflation across horizons. Moreover, looking at the bond-stock correlation across maturities could be useful to test various theories that make predictions about both bond and equity markets.

Second, BHKV show that equity yields predict future growth rates, such as dividend growth, GDP growth, and even consumption growth. For the same sample period, which is obvously fairly short, equity yields predict growth much better than traditional predictor variables such as nominal and real bond yields. Given the large literature in macro on forecasting macro-economic growth using big data, see for instance Stock and Watson (2014) and Beber, Brandt, and Luisi (2014), it would be interesting to explore whether equity yields add information beyond the traditional set of forecast variables.

Third, understanding the link between asset markets and real economic decisions, such as hiring and investment, is at the heart of the macro-finance research agenda. Recent work by Hall (2014) suggests that variation in short-term discount rates may help to explain why hiring is much more volatile than the difference between wages and the marginal product of capital (Shimer 2005). ${ }^{13}$

The same argument holds for investment, where investment is much more volatile than the marginal product of capital. Moreover, investment does not align well with the marketto-book ratio, which is the failure of Q-theory. Following Hall (2014)'s logic, investment decisions are more sensitive to short-term discount rates than overall firm value as a result of depreciation. A firm's overall value includes future growth options, which have a much longer maturity than current investments. Firm-level equity yields, which are currently exchange traded in Europe, can be used to study whether hiring and investment are better aligned with short-term discount rates than market-to-book ratios.

\footnotetext{
${ }^{12}$ See, for instance, Duffee (2002), Dai and Singleton (2003), and Ang and Piazzesi (2003). See Duffee (2012) for a recent summary of the literature.

${ }^{13}$ See also Kehoe, Midrigan, and Pastorino (2014).
} 


\section{REFERENCES}

Ai, H., M. Croce, A. Diercks, and K. Li (2012): "Production Based Term Structure of Equity Returns," Working paper, Unniversity of Minnesota.

Ait-Sahalia, Y., M. Karaman, and L. Mancini (2014): "The Term Structure of Variance Swaps and Risk Premia," Working Paper, Princeton University.

Albuquerque, R. A., M. Eichenbaum, and S. T. Rebelo (2014): "Valuation Risk and Asset Pricing," Unpublished paper, Boston University.

Andries, M. (2014): "Consumption-based Asset Pricing with Loss Aversion," Working Paper, Toulouse School of Economics.

Andries, M., T. Eisenbach, M. Schmalz, and Y. Wang (2015): "The Term Structure of the Price of Volatility Risk," Working Paper, Toulouse School of Economics.

Andries, M., T. M. Eisenbach, And M. C. Schmalz (2014): "Asset Pricing with Horizon-dependent Risk Aversion," Unpublished paper, Toulouse School of Economics.

Ang, A., And M. Piazzesi (2003): "A No-Arbitrage Vector Regression of Term Structure Dynamics with Macroeconomic and Latent Variables," Journal of Monetary Economics, $50,745-787$.

Ang, A., And M. Ulrich (2012): "Nominal Bonds, Real Bonds, and Equity," Working Paper, Columbia University.

Badarinza, C., and T. Ramadorai (2014): "Long-Run Discounting: Evidence from the UK Leasehold Valuation Tribunal," Working Paper, Oxford University.

Baele, L., G. Bekaert, and K. Inghelbrecht (2010): "The Determinants of Stock and Bond Return Comovements," Review of Financial Studies, 23(6), 2374-2428.

Bansal, R., And A. YAron (2004): "Risks for the Long-Run: A Potential Resolution of Asset Pricing Puzzles," Journal of Finance, 59(4), 1481-1509.

BArro, R. (2006): "Rare Disasters and Asset Markets in the Twentieth Century," Quarterly Journal of Economics, August.

Basak, S., And A. Pavlova (2013): "Asset Prices and Institutional Investors," American Economic Review, 103(5), 1728-1758. 
Beber, A., M. W. Brandt, and M. Luisi (2014): "Distilling the Macroeconomic News Flow," Journal of Financial Economics, forthcoming.

Belo, F., P. Collin-Dufresne, and R. S. Goldstein (2014): "Dividend Dynamics and the Term Structure of Dividend Strips," Journal of Finance, forthcoming.

Berk, J., And J. VAn Binsbergen (2014): “Assessing Asset Pricing Models Using Revealed Preference," Working Paper, The Wharton School.

Berrada, T., J. Detemple, and M. Rindisbacher (2013): "Asset Pricing with RegimeDependent Preferences and Learning," Working Paper.

Binsbergen, J. H. V., M. W. Brandt, and R. S. Koijen (2012): "On the Timing and Pricing of Dividends," American Economic Review, 102, 1596-1618.

Binsbergen, J. H. V., W. Hueskes, R. S. Koijen, and E. B. Vrugt (2014): "Equity Yields," Journal of Financial Economics, 110(3), 503-519.

Binsbergen, J. H. V., And R. S. Koijen (2010): "Predictive Regressions: A PresentValue Approach," Journal of Finance, 65, 1439-1471.

Boguth, O., M. Carlson, A. Fisher, and M. Simutin (2011): "Dividend Strips and the Term Structure of Equity Risk Premia: A Case Study of the Limits of Arbitrage," Working Paper, University of British Columbia.

Borovicka, J., L. P. Hansen, M. Hendricks, and J. A. Scheinkman (2009): "Risk Price Dynamics," Working Paper.

Brennan, M. J. (1998): "Stripping the S\&P 500 Index," Financial Analysts Journal, 54, $12-22$.

Campbell, J. Y., and J. H. Cochrane (1999): "By Force of Habit: A ConsumptionBased Explanation of Aggregate Stock Market Behavior," Journal of Political Economy, 107, 205-251.

Campbell, J. Y., A. Sunderam, and L. M. Viceira (2013): "Inflation Bets or Deflation Hedges? The Changing Risks of Nominal Bonds," Working Paper, Harvard University.

Corhay, A., H. Kung, and L. Schmid (2015): "Competition, Markups, and Predictable Returns," Working Paper, University of British Columbia.

Croce, M., M. Lettau, and S. Ludvigson (2014): "Investor Information, Long-Run Risk, and the Term Structure of Equity," Review of Financial Studies, forthcoming. 
Curatola, G. (2014): "Loss Aversion, Habit Formation and the Term Structures of Equity and Interest Rates," Working Paper.

Dai, Q., And K. Singleton (2003): "Term Structure Dynamics in Theory and Reality," Review of Financial Studies, 16, 631-678.

Danthine, J.-P., And J. B. Donaldson (2002): "Labour Relations and Asset Returns," Review of Economic Studies, 69, 41-64.

Dasgupta, A., A. Prat, and M. Verardo (2011): "The Price Impact of Institutional Herding," Review of Financial Studies, 24(3), 892-925.

Dew-Becker, I., S. Giglio, A. Le, and M. Rodriguez (2014): "The Price of Variance Risk," Working Paper, Kellogg.

Duffee, G. R. (2012): "Bond pricing and the Macroeconomy," Working Paper, Johns Hopkins University.

Eisenbach, T. M., And M. C. Schmalz (2014): "Up Close It Feels Dangerous: Anxiety in the Face of Risk," Unpublished paper, Federal Reserve Bank of New York.

Epstein, L., E. Farhi, and T. Stralezcki (2014): "How Much Would You Pay to Resolve Long-Run Risk?," American Economic Review, 104(9), 2680-2697.

Favilukis, J., AND X. Lin (2015): "Wage Rigidity: A Quantitative Solution to Several Asset Pricing Puzzles," Working paper, University of British Columbia.

Gabaix, X. (2009): "Variable Rare Disasters: An Exactly Solved Framework for Ten Puzzles in Macro-Finance," Working paper, NYU.

Giglio, S., M. Maggiori, and J. Stroebel (2014): "Very Long-run Discount Rates," Quarterly Journal of Economics, forthcoming.

Golez, B. (2014): "Expected Returns and Dividend Growth Rates Implied by Derivative Markets," Review of Financial Studies, 27, 790-822.

Gourio, F. (2008): "Disasters and Recoveries," American Economic Review, 98(2), 68-73.

Hall, R. E. (2014): "High Discounts and High Unemployment," Working Paper, Stanford University.

Hansen, L. P., J. C. Heaton, and N. Li (2008): "Consumption Strikes Back? Measuring Long-Run Risk," Journal of Political Economy, 116 (2), 260-302. 
Hansen, L. P., and R. Jagannathan (1991): "Restrictions on Intertemporal Marginal Rates of Substitution Implied by Asset Returns," Journal of Political Economy, 99, 225262.

Hansen, L. P., And J. A. Scheinkman (2009): "Long-Term Risk: An Operator Approach," Econometrica, 77, $177-234$.

Hasler, M., And R. Marfe (2015): "Disaster Recovery and the Term Structure of Dividend Strips," Working Paper, University of Toronto.

He, Z., And A. Krisnamurthy (2013): "Intermediary Asset Pricing," American Economic Review, 103(2), 732-770.

Katz, M., H. N. Lustig, and L. N. Nielsen (2015): “Are Stocks Real Assets?," Working Paper, AQR Capital Management, LLC.

Kehoe, P., V. Midrigan, and E. Pastorino (2014): "Debt Constraints and Employment," Working Paper, University of Minnesota.

Koijen, R. S., And M. Yogo (2015): "An Equilibrium Model of Institutional Demand and Asset Prices," .

Kragt, J., F. De Jong, And J. Driessen (2014): "The Dividend Term Structure," Unpublished paper, Tilburg University.

Lettau, M., and S. C. Ludvigson (2005): "Expected Returns and Expected Dividend Growth," Journal of Financial Economics, 76, 583-626.

Lettau, M., and J. A. Wachter (2007): "Why is Long-Horizon Equity Less Risky? A Duration-Based Explanation of the Value Premium," Journal of Finance, 62, 55-92.

(2011): "The Term Structures of Equity and Interest Rates," Journal of Financial Economics, (101), 90-113.

Lustig, H., And S. V. Nieuwerburgh (2006): "Exploring the Link between Housing and the Value Premium," Working paper, UCLA.

Luttmer, E. G. J. (1996): "Asset Pricing in Economies with Frictions," Econometrica, $64(6), 1439-1467$.

Lynch, A., And O. Randall (2011): "Why Surplus Consumption in the Habit Model May be Less Persistent than You Think," Working paper. 
Marfe, R. (2014a): "Corporate Fraction and the Equilibrium Term Structure of Equity Risk," Review of Finance, forthcoming.

(2014b): "Demand Shocks, Timing Preferences and the Equilibrium TermStructures," Unpublished paper.

(2014c): "Income Insurance and the Equilibrium Term-Structure of Equity," Unpublished paper.

Nakamura, E., J. Steinsson, R. J. Barro, and J. Ursua (2013): "Crises and Recoveries in an Empirical Model of Consumption Disasters," American Economic Journal: Macroeconomics, 5(3), 157-188.

Palhares, D. (2012): "Cash-Flow Maturity and Risk Premia in CDS Markets," Working Paper, University of Chicago.

Rangvid, J., M. Schmeling, and A. Schrimpf (2014): "Dividend Predictability Around the World," Journal of Financial and Quantitative Analysis (Forthcoming).

Schulz, F. (2013): "On the Timing and Pricing of Dividends: Revisiting the Term Structure of the Equity Risk Premium," Working paper, Michael G. Foster School of Business.

Shiller, R. J. (1981): "Do Stock Prices Move Too Much to be Justified by Subsequent Changes in Dividends?," American Economic Review, 71, 421-436.

Shimer, R. (2005): "The Cyclical Behavior of Equilibrium Unemployment and Vacancies," American Economic Review, 95(1), 24-49.

Stock, J. H., and M. W. Watson (2014): "Estimating Turning Points using Large Data Sets," Journal of Econometrics, 178, 368-381.

Vayanos, D., And P. Woolley (2013): "An Institutional Theory of Momentum and Reversal," Review of Financial Studies, 26(5), 1087-1145.

Wachter, J. (2005): "Solving Models with External Habit," Finance Research Letters, 2, 210-226.

Wachter, J. A. (2010): "Can Time-varying Risk of Rare Disasters Explain Aggregate Stock Market Volatility?," Working Paper.

YAN, W. (2014): "Estimating a Unified Framework of Co-Pricing Stocks and Bonds," Working Paper, London School of Economics. 


\section{A. Decomposing Index Returns}

Let the stock index level $P_{t}$ be given by the sum of dividend strip (spot) prices $P_{t, n}$ :

$$
S_{t}=\sum_{n=1}^{\infty} P_{t, n} .
$$

Further define the maturity 0 dividend spot price as:

$$
P_{t, 0} \equiv D_{t}
$$

where $D_{t}$ is the dividend paid out at time $t$. Recall that dividend strip spot returns are given by:

$$
R_{t, n}^{S}=\frac{P_{t, n-1}}{P_{t-1, n}}-1
$$

and dividend futures returns by:

$$
R_{t, n}^{F}=\frac{F_{t, n-1}}{F_{t-1, n}}-1
$$

Now we can write total returns on the index $R_{t}^{M}$ as:

$$
\begin{aligned}
1+R_{t}^{M} & =\frac{S_{t}+D_{t}}{S_{t-1}} \\
& =\frac{\sum_{n=1}^{\infty} P_{t, n-1}}{\sum_{n=1}^{\infty} P_{t-1, n}} \\
& =\sum_{n=1}^{\infty} w_{t-1, n} \frac{P_{t, n-1}}{P_{t-1, n}} \\
& =\sum_{n=1}^{\infty} w_{t-1, n}\left(1+R_{t, n}^{S}\right)
\end{aligned}
$$

where

$$
w_{t-1, n}=\frac{P_{t-1, n}}{S_{t-1}}
$$

and thus:

$$
\sum_{n=1}^{\infty} w_{t-1, n}=1
$$


Now using that:

$$
P_{t, n}=F_{t, n} \exp \left(-n y_{t, n}\right)
$$

we have for each dividend strip return:

$$
\begin{aligned}
R_{t, n}^{S} & =\frac{P_{t, n-1}}{P_{t-1, n}}=\frac{F_{t, n-1} \exp \left(-(n-1) y_{t, n-1}\right)}{F_{t, n} \exp \left(-n y_{t-1, n}\right)} \\
& =\left(1+R_{t, n}^{F}\right)\left(1+R_{t, n}^{B}\right) \approx 1+R_{t, n}^{F}+R_{t, n}^{B}
\end{aligned}
$$

Therefore we can write for the index return:

$$
R_{t}^{M}=\sum_{n=1}^{\infty} w_{t-1, n} R_{t, n}^{S} \approx \sum_{n=1}^{\infty} w_{t-1, n} R_{t, n}^{F}+\sum_{n=1}^{\infty} w_{t-1, n} R_{t, n}^{B}
$$

Rearranging, we find:

$$
\sum_{n=1}^{\infty} w_{t-1, n} R_{t, n}^{F}=R_{t}^{M}-\sum_{n=1}^{\infty} w_{t-1, n} R_{t, n}^{B}
$$

Now the only question left is how we approximate the return on the bond portfolio:

$$
\sum_{n=1}^{\infty} w_{t-1, n} R_{t, n}^{B}
$$

We approximate this bond portfolio by the 10-year bond return, but given the high duration of stocks, higher maturities could easily be used. 